\title{
Enhancement in Heat Exchange Process in a Shell and Tube Heat Exchanger using Nano-Particles
}

\author{
Yogesh Sharma, Neeraj Yadav
}

\begin{abstract}
Nanoparticles and nano-fluids are having its significant role in transforming and improvising the existing tools and techniques of science and other research. This experimental study deals with the parametric analysis of $\mathrm{Al}_{2} \mathrm{O}_{3}$ of size 20-30 nm and $\mathrm{CuO}$ of size 30-50 $\mathrm{nm}$ nanoparticles to improve the effectiveness of a shell and tube heat exchanger. Nanoparticles used in heat exchangers improved performance through better heat transfer characteristics. An experimental investigation was done on the forced convective heat transfer and flow characteristics of the nano-fluid flowing in a horizontal shell and tube heat exchanger under turbulent flow conditions. The heat transfer of nano-fluid is found higher than that of the base liquid at same mass flow rate and temperature difference. The heat transfer thus heat transfer parameters increases with an increase in volume concentration up to $1.6 \%$ after which heat transfer decreases due to viscosity effects.
\end{abstract}

Keywords : Effectiveness, Heat Exchanger, Heat Transfer parameters, Nanoparticles.

\section{INTRODUCTION}

Heat exchangers are the units that exchanges heat between two or more fluids by the virtue of temperature gradient because of the temperature difference. Two or more fluids may be in direct or indirect contact for exchanging the heat with each other depending on the compactness, heat load and nature of fluid under the process. Heat exchangers finds wide application in various industries, process as well as commercial. Heat exchangers now are the integral part of electronic circuits and other electrical appliances. Other industries for the application includes food industry, chemical industry, manufacturing, refrigeration and air conditioning and other space applications. Nearly a decade ago, the nano-techniques have reached different heights with remarkable advancement in various scientific applications, where the size of nanoparticles have shrinked from micrometers to nanometers upto $100 \mathrm{~nm}$ [1]

. When these nanoparticles gets dispersed in the base fluid they are termed as nano-fluids. This term was suggested by Choi in 1995[2] and since then this term has gained the popularity. Several research works have been carried by

Revised Manuscript Received on February 15, 2020.

* Correspondence Author

Yogesh Sharma*, research scholar M.E. / M.Tech. specialization in Thermal Engineering , Medi-caps University, Indore, India.

Asst. prof. Neeraj Yadav, Assisstant Professor, Medi-caps University, Indore, India.

(C) The Authors. Published by Blue Eyes Intelligence Engineering and Sciences Publication (BEIESP). This is an open access article under the CC BY-NC-ND license (http://creativecommons.org/licenses/by-nc-nd/4.0/) various researchers where the heat transfer phenomenon and the flow characteristics have been investigated and got the results in positive direction with few challenges. Abu-Nada,[3]studied heat transfer through natural convection using $\mathrm{CuO}$ nano-fluid using finite volume method in a differentially heated enclosure.His findings reveals that the friction factor and dynamic viscosity increases on dispersing nanoparticles into the base fluid. Chein and Chuang[4] used $\mathrm{CuO}$ nano-fluid as coolant in microchannel heat sink. Various equations have been used to calculate several thermal and physical properties of nano-fluids. Nanotechnology includes the structure where the size ranges from $1 \mathrm{~nm}$ to100 nm. As per the Royal Society and Royal Academy of Engineering [5] Nano materials are the building blocks of the nanotechnology with size ranging between $1 \mathrm{~nm}$ to $100 \mathrm{~nm}$ and detailed study of its thermo-physical properties for application is needed. The project deals with the use of Aluminum oxide, $\mathrm{Al}_{2} \mathrm{O}_{3}$ (20-30 $\mathrm{nm}$ ) and Copper Oxide , $\mathrm{CuO}$ (30-50 nm) nanoparticles individually to improve the effectiveness of a shell and tube heat exchanger by analyzing various parameters related to it A shell and tube heat exchanger with four tube and a shell is used for the investigation. Water is selected to flow in the shell side as cold fluid and nano-fluid is selected to flow in the tube side in this investigation.

\section{Equations and Formulas Used}

1. Density for the nanofluid given by Pak and Cho relation[6] $\rho_{n f}=(1-\emptyset) \rho_{f}+\emptyset \rho_{p}$

Where,

$\rho_{\mathrm{nf}}$ - Density of the nanofluid

ø - Particles volume concentration

$\rho_{\mathrm{f}} \quad$ - Density of the base fluid and

$\rho_{\mathrm{p}} \quad$ - Density of the nanoparticles.

2. Specific heat is calculated by Zuan and Roetzel relation[7]

$$
\left(\rho C_{p}\right)_{n f}=(1-\emptyset)\left(\rho C_{p}\right)_{f}+\emptyset\left(\rho C_{p}\right)_{p}
$$

Where,

$$
\begin{aligned}
& C_{p n f} \text { - Heat capacity of the nanofluid, } \\
& C_{p f} \text { - Heat capacity of the base fluid and } \\
& C_{p p} \text { - Heat capacity of the nanoparticle. }
\end{aligned}
$$

3.Thermal conductivity formula for nanofluid was introduced by $\mathrm{Yu}$ and Choi[8] 


\section{Enhancement in Heat Exchange Process in a Shell and Tube Heat Exchanger using Nano-Particles}

$$
K_{n f}=k_{f} \frac{\left(K+2 K_{f}-2 \emptyset\left(K_{f}-K\right)\right.}{\left(K+2 K_{f}+\emptyset\left(K_{f}+K\right)\right.}
$$

4. The viscosity of the nanofluid was given by Drew and Passman[9]

$$
\mu_{n f}=(1+2.5 \emptyset) \mu_{w}
$$

Where,

$$
\begin{aligned}
& \mu_{\mathrm{nf}} \text { - Nano fluid viscosity } \\
& \mu_{\mathrm{w}} \quad \text { - water viscosity }
\end{aligned}
$$

5. Thermal Diffusivity is given by

$$
\propto_{n f}=\frac{K_{n f}}{\rho_{n f} C_{p}}
$$

6. Prandtl number[10]

$$
\operatorname{Pr}=\frac{v_{n f}}{\propto_{n f}}
$$

7. Nusselt number

$$
N u=\frac{(0.125 f)(R e-1000) P r}{1+12.7(0.125 f)^{5}\left(\mathrm{Pr}^{2 / 3}-1\right)}
$$

8. Kinematic viscosity

$$
v=\frac{\mu}{\rho}
$$

9. Calculations of Reynold's No.[11]

$$
R e=\frac{V D \rho}{\mu}
$$

Where,

$$
\begin{aligned}
& \text { V - Fluid Velocity } \\
& \text { D - Tube Diameter }
\end{aligned}
$$

10. Peclet Number

$$
\mathrm{Pe}=\mathrm{Re} * \mathrm{Pr}
$$

11. Heat transfer rate

$$
q=\dot{m} c_{p} \Delta t
$$

Where,

q - Heat transfer rate

m - Mass flow rate

$\Delta \mathrm{t}$ - temperature difference of the cooling liquid

12. The logarithmic temperature difference

$$
\Delta \mathrm{T}_{\ln }=\frac{(\text { Twi }- \text { Tno })-(\text { Twi }-T \text { Tni })}{\operatorname{Ln}((\text { Twi }- \text { Tno }) /(\text { Twi }- \text { Tni }))}
$$

Where,

$\Delta \mathrm{T}_{\mathrm{lm}}$ - Logarithmic temperature difference,

$\mathrm{T}_{\mathrm{wi}}$ - Inlet temperature of the water,

$\mathrm{T}_{\mathrm{wo}} \quad$ - Outlet temperature of water,

$\mathrm{T}_{\mathrm{ni}} \quad$ - Inlet temperature of the nanofluid and

$\mathrm{T}_{\mathrm{n}} \quad$ - Outlet temperature of the nanofluid.
13. Overall heat transfer coefficient

$$
q=U A_{s} \Delta T_{l m}
$$

Where,
U - Overall heat transfer coefficient
$\mathrm{A}_{\mathrm{S}}$-Surface temperature

\section{EXPERIMENTAL SETUP}

Fig.1. and Fig.2. shows a shell and tube heat exchanger consisting of a shell and four tubes is used to analyze the behavior of aluminum oxide $\mathrm{Al}_{2} \mathrm{O}_{3}$ and copper oxide $\mathrm{CuO}$ in the base fluid that is distilled water. Here forced convection is used for the counter-flow action between the base fluid and nano-fluid containing aluminum oxide and copper oxide respectively. First of all, distilled water as base fluid was tested for various flow rates and its heat transfer and other parameters. Then at the flow rate of $0.000016 \mathrm{~m}^{3} / \mathrm{s}$ and $0.000014 \mathrm{~m}^{3} / \mathrm{s}$ at various concentration of nano-fluid consisting aluminum oxide and copper oxide was examined. Water was kept on the shell side and taken as the colder fluid and nano-fluid was kept on the tube side and was taken as hotter fluid.The temperatures at inlet and outlet of water and nano-fluid were recorded, then calculations for the heat transfer and other parameters was done using empirical Maxwell and other co-relations.

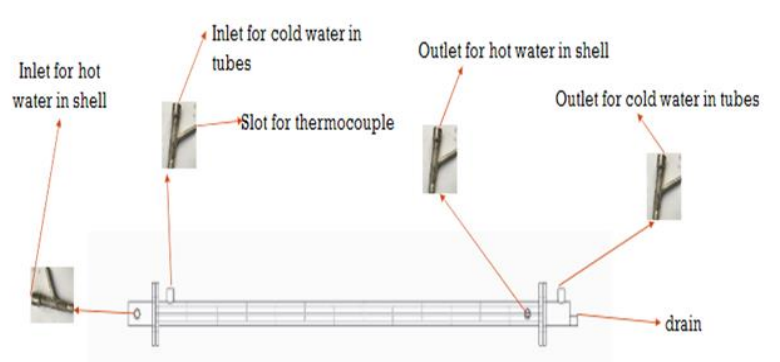

Fig.1. Skeleton view of Experimental set up

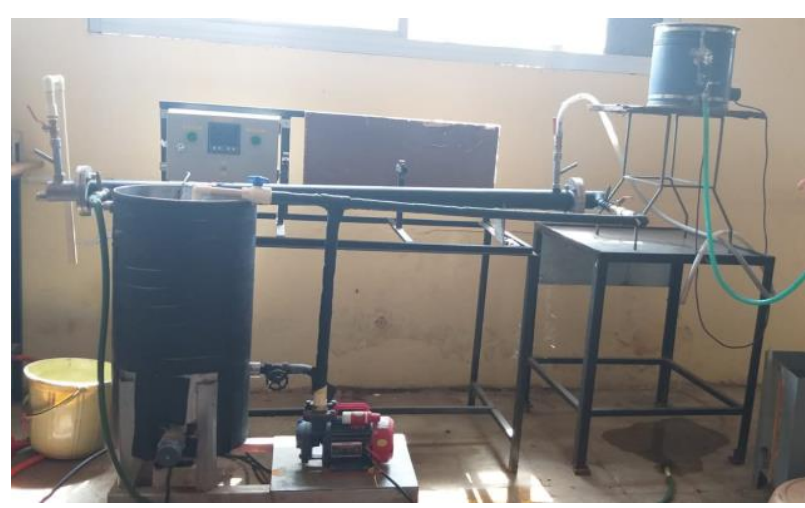

Fig.2. Experimental set up

III. RESULTS AND DISCUSSION 
Table 1. Analysis of heat transfer parameters with variation in concentration and selected flow rates

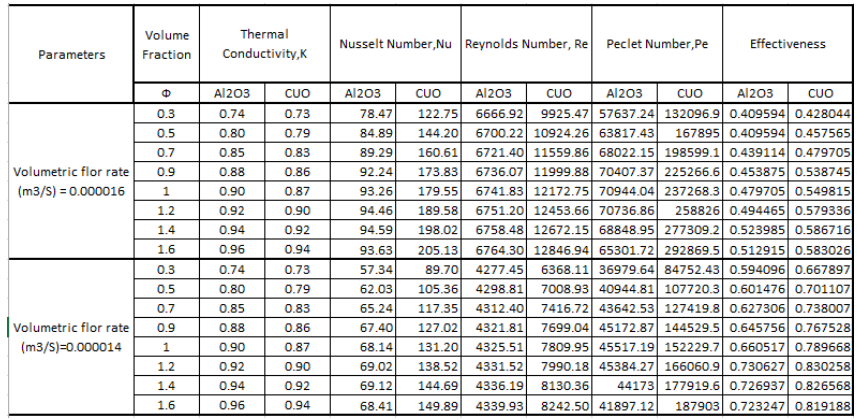

Based on the Table 1. above the following graphs from Fig.1.3 to Fig. 1.12 below are plotted. At the definite flow rate for various concentration, the various parameters such as Thermal Conductivity, Nusselt Number, Reynolds Number, Peclet Number and Effectiveness for both the nano-fluids is analyzed.

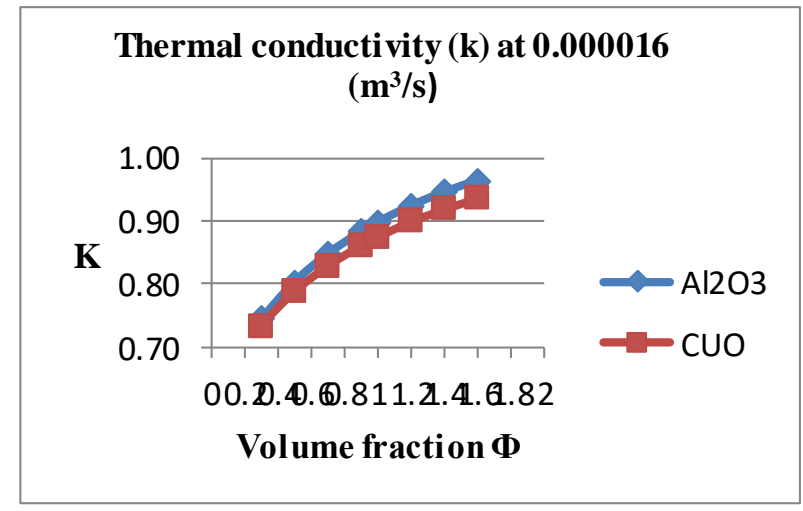

Fig.3. Thermal conductivity $(\mathrm{k})$ at $0.000016\left(\mathrm{~m}^{3} / \mathrm{s}\right)$

Fig.3. shows that Thermal conductivity for both aluminum oxide and copper oxide nano-fluid ,thermal conductivity is maximum at $1.6 \%$ of the volumetric concentration between the same temperature limits for shell side base fluid and tube side nano-fluid at $0.000016 \mathrm{~m}^{3} / \mathrm{s}$ of volume flow rate. It can also be inferred that the nano-fluid containing aluminum oxide is having higher thermal conductivity as compared to copper oxide.

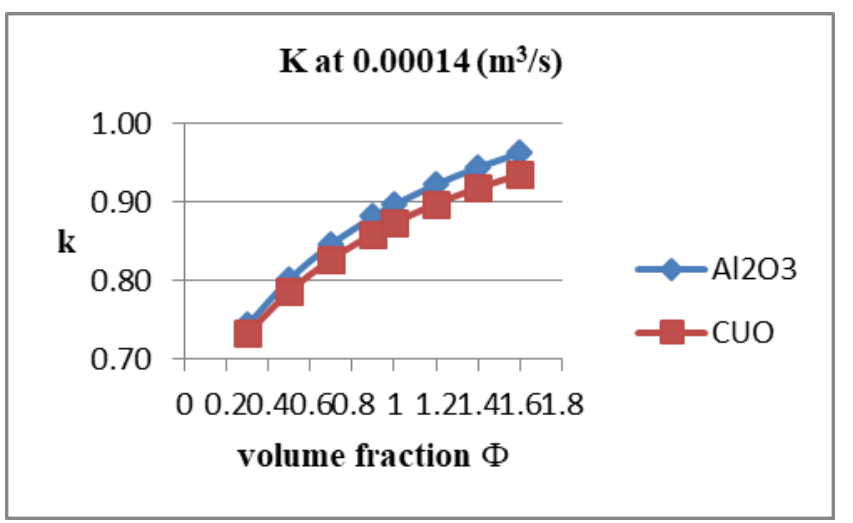

Fig.4. Thermal Conductivity (k) at $0.000014\left(\mathrm{~m}^{3} / \mathrm{s}\right)$

Fig.4. shows that Thermal conductivity for both aluminum oxide and copper oxide nano-fluid thermal conductivity is maximum at $1.6 \%$ of the volumetric concentration between the same temperature limits for shell side base fluid and tube side nano-fluid at $0.000014 \mathrm{~m}^{3} / \mathrm{s}$ of volume flow rate. It can also be inferred that the nano-fluid containing aluminum oxide is having higher thermal conductivity as compared to copper oxide.

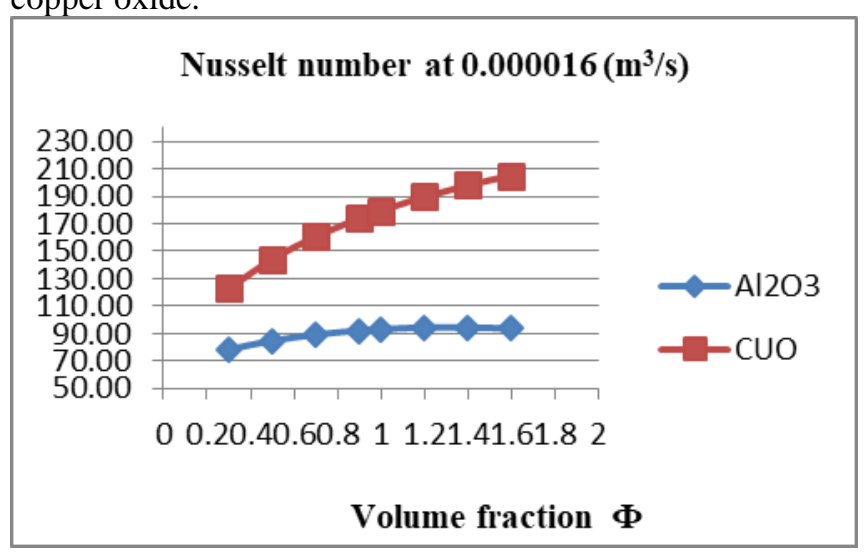

Fig.5. Nusselt number at $0.000016\left(\mathrm{~m}^{3} / \mathrm{s}\right)$

Fig.5. shows that Nusselt number for $\mathrm{CuO}$ nano-fluid is higher in comparison with $\mathrm{Al}_{2} \mathrm{O}_{3}$. Further it inferred that for Aluminum oxide Nusselt number is higher at $1.4 \%$ concentration and for copper oxide Nusselt number is most significant at $1.6 \%$ at the flow rate of $0.000016 \mathrm{~m}^{3} / \mathrm{s}$.

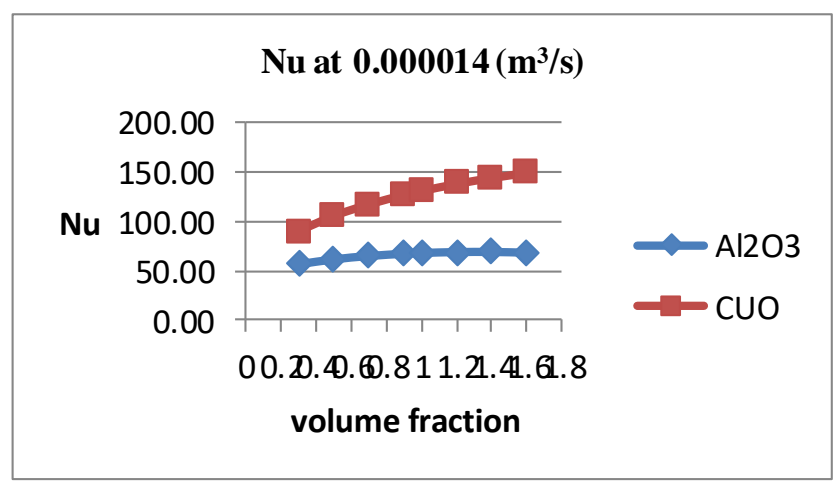

Fig.6. Nusselt number at $0.000014\left(\mathrm{~m}^{3} / \mathrm{s}\right)$

Fig.6. shows that Nusselt number for $\mathrm{CuO}$ is higher in comparison with $\mathrm{Al}_{2} \mathrm{O}_{3}$ nano-fluid. Further it inferred that for Aluminum oxide Nusselt number is higher at $1.4 \%$ concentration and for copper oxide Nusselt number is most significant at $1.6 \%$ at the flow rate of $0.000014 \mathrm{~m}^{3} / \mathrm{s}$.

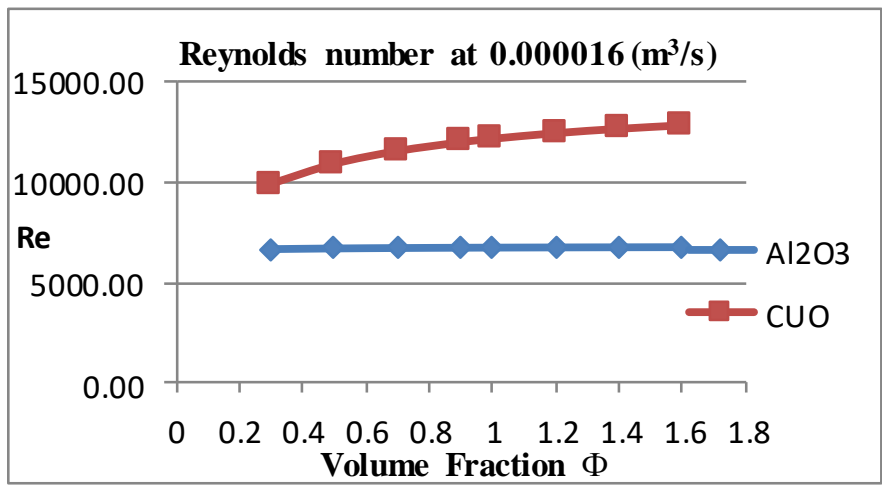

Fig.7. Reynolds number at $0.000016\left(\mathrm{~m}^{3} / \mathrm{s}\right)$

Published By:

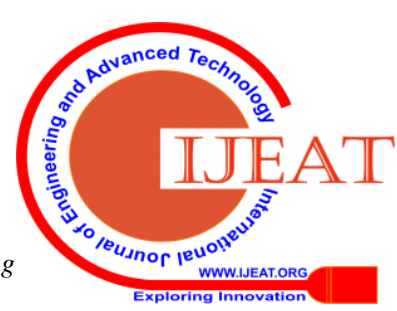


Fig.7. shows that Reynolds number and hence the turbulence needed for heat transfer is maximum at $1.6 \%$ concentration for both aluminum oxide and copper oxide at the flow rate of $0.000016 \mathrm{~m}^{3} / \mathrm{s}$. Further it is inferred that the nano-fluid having copper oxide gives the better result than nano-fluid having aluminum oxide.

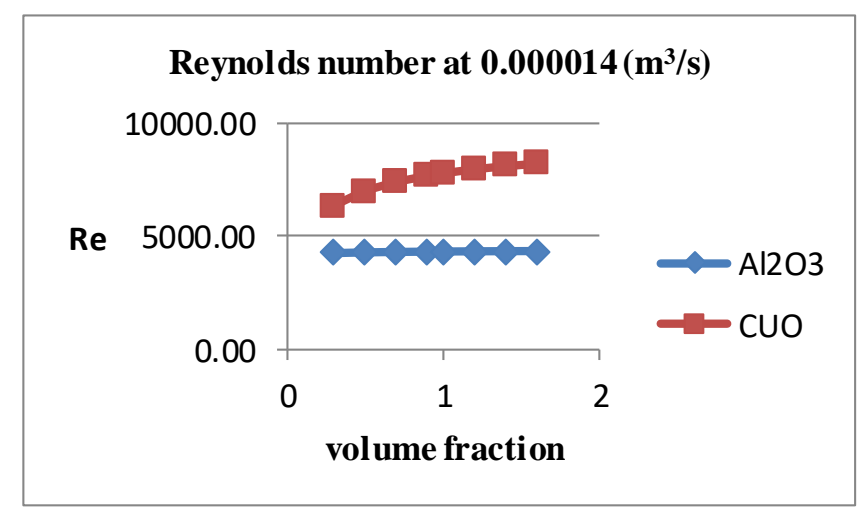

Fig.8. Reynolds number at $0.000014\left(\mathrm{~m}^{3} / \mathrm{s}\right)$

Fig.8. shows that Reynolds number and hence the turbulence needed for heat transfer is maximum at $1.6 \%$ concentration for both aluminum oxide and copper oxide at the flow rate of $0.000014 \mathrm{~m}^{3} / \mathrm{s}$. Further it is inferred that the nano-fluid having copper oxide gives the better result than nano-fluid having aluminum oxide.

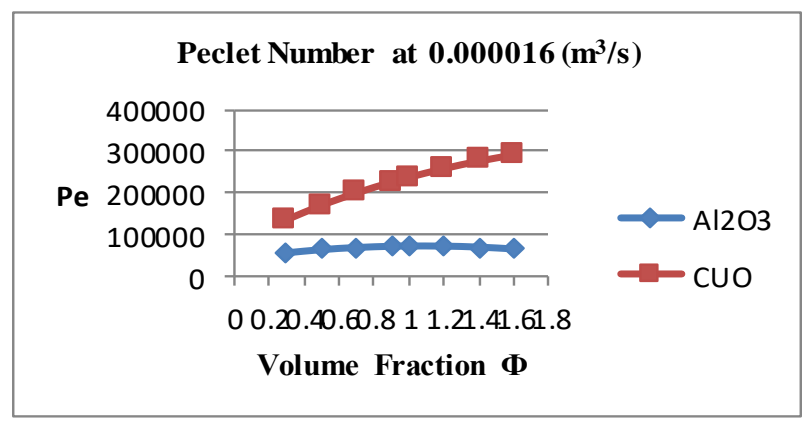

Fig.9. Peclet Number at $0.000016\left(\mathrm{~m}^{3} / \mathrm{s}\right)$

Fig.9. shows the Peclet number and hence the diffusion needed for heat transfer is maximum at around $1 \%$ concentration for aluminum oxide and at $1.6 \%$ for copper oxide at the flow rate of $0.000016 \mathrm{~m}^{3} / \mathrm{s}$. Further it is inferred that the nano-fluid having copper oxide gives the better result than nano-fluid having aluminum oxide.

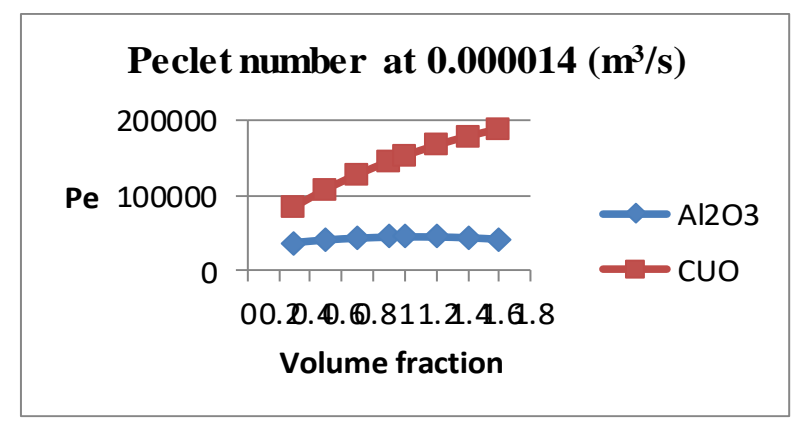

Fig.10. Peclet Number at $0.000014\left(\mathrm{~m}^{3} / \mathrm{s}\right)$

Fig.10. shows that Peclet number and hence the diffusion needed for heat transfer is maximum at around $1 \%$ concentration for aluminum oxide and at 1.6\% for copper oxide at the flow rate of $0.000014 \mathrm{~m}^{3} / \mathrm{s}$. Further it is inferred that the nano-fluid having copper oxide gives the better result than nano-fluid having aluminum oxide.

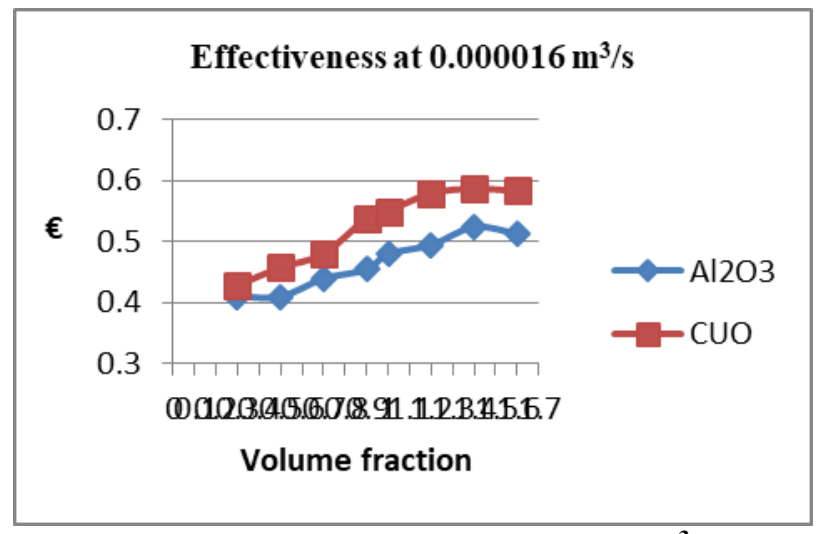

Fig.11. Effectiveness at $0.000016 \mathrm{~m}^{3} / \mathrm{s}$

Fig.11.shows that at $0.000016 \mathrm{~m}^{3} / \mathrm{s}$ flow rate the effectiveness increases from $0.3 \%$ to around $1.6 \%$ and tends to decrease from $1.6 \%$ of nano-fluid for both the alumina oxide and copper oxide.This happens because of the increase in viscosity due to addition of nanoparticles[1].

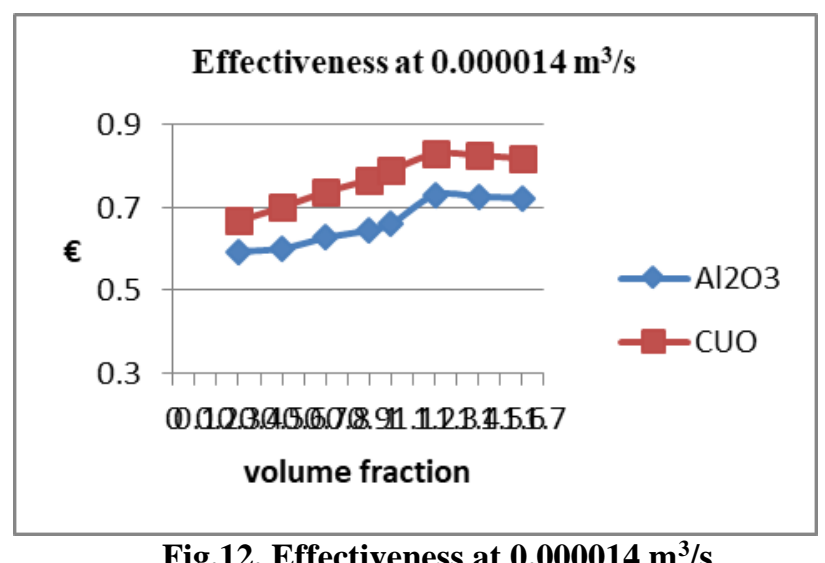

Fig.12. Effectiveness at $0.000014 \mathrm{~m}^{3} / \mathrm{s}$

Fig.12. shows that at $0.000014 \mathrm{~m}^{3} / \mathrm{s}$ flow rate, the effectiveness increases from $0.3 \%$ to around $1.6 \%$ and tends to decrease from $1.6 \%$ of nano-fluid for both the alumina oxide and copper oxide.This happens because of the increase in viscosity due to addition of nanoparticles[1].

\section{CONCLUSION}

From the above discussion it can be concluded that at the flow rate of $0.000016 \mathrm{~m}^{3} / \mathrm{s}$ and $0.000014 \mathrm{~m}^{3} / \mathrm{s}$ the Thermal Conductivity for aluminum oxide is more than copper oxide and for rest of the parameters that is Nusselt Number , Reynolds Number, Peclet Number and effectiveness nano-fluid containing copper oxide gave the better results than aluminum oxide. It is also concluded that the above mentioned parameters tends to increase from $0.3 \%$ to $1.6 \%$ concentration for both the nano-fluids after which it tends to decrease. 
Thus from the above analysis it can be said that copper oxide gives better results with respect to aluminum oxide at all concentration on the basis of diffusion rate in turbulent flow.

\section{Publication:}

> Varun Yadav, S.Panual, Neeraj Yadav et.al. "Design and Fabrication of Solar Powered Vapour Absorption Refrigration System" $6^{\text {th }}$ International Conference on Energy and City of the Future (EVF '19) organized by MIT School of Engineering, Pune, India during Dec 18 to 20, 2019.

$>$ Neeraj Yadav and Dr. Govind Maheshwari, "Analysis of Carnot Cycle, Based on Entropy Generation Principle, with Variable Heat source and Heat sink temperature" Peripex- Indian Journal of Research ISSN - 2250-1991 Volume: 4 Issue : 8 Aug 2015.

$>$ Prabhat Patel and Neeraj Yadav, "Modification in heat exchanger named as "COILED FLOW" heat exchanger" All India Seminar on Design and Analysis of Mechanical Systems using Optimization Techniques at IET-DAVV Indore on 14-15 October, 2011.

$>$ Vinay Vakharia, Himansu Borade, Neeraj Yadav, Ansuman Purohit "Parametric Design and Analysis of Rectangular Duct Using Design of Experiment" National Conference on "Advances in Thermal Engineering"NCATE - 2011 Friday, 14 October 2011. $>$ K. K. Gupta, Dr. S.C. Sharma, Neeraj Yadav "Application of Karanja Bio-Diesel in Single Cylinder 4-Stroke Diesel Engine" National Conference on "Advances in Thermal Engineering" NCATE - 2011 Friday, 14 October 2011.

\section{REFERENCES}

1. J. Albadr, S. Tayal, and M. Alasadi, "Heat transfer through heat exchanger using $\mathrm{Al} 2 \mathrm{O} 3$ nanofluid at different concentrations," Case Studies in Thermal Engineering, vol. 1, pp. 38-44, 2013.

2. S. U. Choi and J. A. Eastman, "Enhancing thermal conductivity of fluids with nanoparticles," Argonne National Lab., IL (United States)1995.

3. E. Abu-Nada and A. J. Chamkha, "Effect of nanofluid variable properties on natural convection in enclosures filled with a CuO-EG-water nanofluid," International Journal of Thermal Sciences, vol. 49, pp. 2339-2352, 2010.

4. R. Chein and J. Chuang, "Experimental microchannel heat sink performance studies using nanofluids," International Journal of Thermal Sciences, vol. 46, pp. 57-66, 2007.

5. V. Shah and I. Belozerova, "Influence of Metal Nanoparticles on the Soil Microbial Community and Germination of Lettuce Seeds," Water, Air, and Soil Pollution, vol. 197, pp. 143-148, 02/01 2009.

6. B. C. Pak and Y. I. Cho, "HYDRODYNAMIC AND HEAT TRANSFER STUDY OF DISPERSED FLUIDS WITH SUBMICRON METALLIC OXIDE PARTICLES," Experimental Heat Transfer, vol. 11, pp. 151-170, 1998/04/01 1998.

7. Y. Xuan and W. Roetzel, "Conception for Heat Transfer Correlation of Nanofluids," International Journal of Heat and Mass Transfer - INT J HEAT MASS TRANSFER, vol. 43, pp. 3701-3707, 10/01 2000.

8. W. Yu and S. U. S. Choi, "The role of interfacial layers in the enhanced thermal conductivity of nanofluids: a renovated Maxwell model," Journal of nanoparticle research, vol. 5, pp. 167-171, 2003.

9. D. A. Drew and S. L. Passman, Theory of multicomponent fluids vol. 135: Springer Science \& Business Media, 2006.

10. F. M. White and I. Corfield, Viscous fluid flow vol. 3: McGraw-Hill New York, 2006.

11. N. Rott, "Note on the history of the Reynolds number," Annual review of fluid mechanics, vol. 22, pp. 1-12, 1990.

\section{AUTHORS PROFILE}

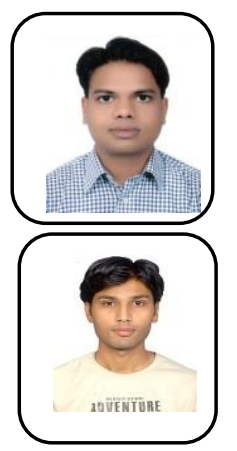

Yogesh Sharma, Presently a research scholar M.E. / M.Tech. with specialization in Thermal Engineering ,Medi-caps University, Indore B.E. Mechanical Engineering Medi-caps Institute Of Technology and Management Indore, RGPV Bhopal. 2011

Asst. prof. Neeraj Yadav, Assisstant Professor at Medi-caps University, Indore Master of Engineering with specialization in "Design And Thermal Engineering" IET DAVV,Indore 2015. BE Mechanical Engineering IIST, Indore , RGPV Bhopal 2009 